\title{
Expatriate Selection: An Empirical Study Identifying Significant Skill Profiles
}

\author{
Andrea Graf
}

\begin{abstract}
Executive Summary
Effective selection procedures constitute an important factor in increasing expatriate success. However, research lacks findings regarding which skills to screen in international selection processes and whether to base expatriate selection on a culture-specific or culture-general skill profile. In an attempt to gather such evidence, an empirical study was conducted in the United States and Germany. Managers in both nations judge intercultural communication skills and intercultural sensitivity to be important intercultural competencies. Moreover, culture-specific skills seem to be required when engaged in both a U.S. and German working context. Recommendations for complementing culture-general and culture-specific skill profiles are discussed. () 2004 Wiley Periodicals, Inc.
\end{abstract}

he issue of international assignments has become increasingly important for multinational cooperations (Kraimer, Wayne, \& Jaworski, 2001; Shaffer, Harrison, \& Gilley, 1999). For example, expatriates are used to transfer technologies, in joint ventures, to transmit organizational culture, to enter new markets, and to develop the international skills of employees (Bennett, Aston, \& Colquhoun, 2000). However, expatriation involves a considerable risk for companies regarding the success of expatriate endeavors and the cost of expatriate failures. Using a broad definition of failure (i.e., the expatriate assignment did not accomplish the goals of the company or the expatriate broke off the assignment), global failure rates have been estimated at $16-40 \%$ (Shaffer et al., 1999), 20-40\% (Solomon, 1996), 30-50\% (Black, Mendenhall, \& Oddou, 1991), and 50\% (Allerton, 1997). The average estimated monetary cost of an expatriate failure is placed at anywhere from $\$ 200,000$ to $\$ 1.2$ million (Copeland \& Griggs, 1986; Solomon, 1996; Swaak, 1995), depending

Dr. Andrea Graf is lecturer at the Department of Business Administration and Economics at the Technical University of Braunschweig in Germany. In her academic research, she focuses on international management and intercultural competence. For several years, Dr. Graf has worked in management development for a large pharmaceutical company. E-mail: a.graf@tu-bs.de.

Thunderbird International Business Review, Vol. 46(6) 667-685 • November-December 2004

(C) 2004 Wiley Periodicals, Inc. • Published online in Wiley InterScience (www.interscience.wiley.com).

DOI: $10.1002 /$ tie. 20030 
on the number of expatriates in the company, the function of the expatriate, and the number of accompanying family members.

Effective expatriate selection has been identified as a major mechanism to enhance expatriate success (Bolino \& Feldman, 2000; Kealey, 1996; Solomon, 1996). Increased emphasis is being placed on utilizThe purpose of ing selection procedures that go beyond technical skills and assess facthis article is to tors such as intercultural skills (Bennett et al., 2000; Forster, 2000). gather evidence To date, researchers have investigated a number of personal characfor effective skill teristics and skills hypothesized to be predictive of competent interprofiles in expa- action with culturally different others (Abe \& Wiseman, 1983; triate selection. Dinges \& Baldwin, 1996; Hammer, Nishida, \& Wiseman, 1996; Kealey, 1989; Ruben, 1976), resulting in a list of potentially useful factors. However, expatriate selection procedures are limited due to the rarity of existing evidence about significant intercultural competencies for international tasks.

One controversy in expatriate selection refers to the question of whether to select expatriates based on a culture-specific or culturegeneral profile. Some authors recommend developing a specific skill profile for every country expatriates are sent to and selecting personnel based on these profiles (e.g., Boles, 1997; Swaak, 1995). However, some authors state a prototype of a successful expatriate and, consequently, the benefit of a culture-general profile. For example, Kealey and Ruben (1983) describe the "ideal" expatriate as ". . . an individual who is truly open to and interested in other people and their ideas, capable of building relationships of trust among people. He or she is sensitive to the feelings and thoughts of another, expresses respect and positive regard for others, and is non-judgemental. Finally, he or she tends to be self-confident, is able to take initiative, is calm in situations of frustration and of ambiguity, and is not rigid. The individual also is a technically or professionally competent person" (p. 165 ).

The purpose of this article is to gather evidence for effective skill profiles in expatriate selection. One objective in the current work is to identify significant intercultural competencies for international tasks. The second objective deals with the controversy of whether to select expatriates based on culture-specific or culturegeneral profiles.

To this end, a study in the United States and Germany is conducted. Methodological reasons guided the choice of the sample. Evaluating capabilities and characteristics in different nations requires measures 
that are valid in the countries as far as both the language and the culture are concerned (Berry, 1989). In the evaluated nations, numerous scientific questionnaires assessing (intercultural) competencies are available, whereas some of them have been validated in a U.S. as well as in a German version.

\section{DEVELOPING THE RESEARCH QUESTIONS}

The current study consists of a qualitative and

The current study consists of a qualitative and a quantitative part. In a quantitative the qualitative section, managers from various companies in the United States and Germany specify intercultural competencies based on their experience. In this part, the first research question is related to the issue of significant intercultural competencies for expatriate selection. The second research question seeks to analyze differences between the U.S. and German samples. This comparison indicates whether the same skill profile is seen to be important in the two nations.

The two research questions in the qualitative part of the study are as follows:

\section{Research Question 1a:}

Which competencies have U.S. and German managers experienced to be important when working with individuals from another nation?

\section{Research Question 1b:}

Do the competencies identified as being significant by U.S. managers differ from those identified as being significant by German managers?

The second part of the study is based on findings from an international literature research. The purpose of this literature research has been to compile skills and capabilities that have been identified to facilitate intercultural interactions in various studies. They are referred to as intercultural competencies. The objective of this part of the study is to verify the importance of these competencies for international tasks. To this end, U.S. and German managers are interviewed about the importance of the identified intercultural competencies in their international work. The data gathered in this part of the study are quantitative. The third research question asks for the importance of the intercultural competencies for international tasks, whereas the last research question analyzes whether the same skill profile is seen to be important in the two nations. 
The two research questions in the quantitative part of the study are as follows:

\section{Research Question 2a:}

Which intercultural competencies identified in literature are rated to

Only students

having already

worked with

people from

another nation

are included in

the study.

be important for international tasks by U.S. and German managers?

\section{Research Question 2b:}

Do the results about the importance of intercultural competencies in the quantitative study differ between the U.S. and German samples?

Summing up, research questions la and 2a relate to the objective of the article to gather evidence for effective skill profiles in expatriate selection. The purpose of research questions $\mathrm{lb}$ and $2 \mathrm{~b}$ is to get to know more about the controversy of culture-specific versus culturegeneral skill profiles in international selection procedures.

\section{METHODS}

\section{Samples}

For the study, matched samples in the United States and Germany are chosen. In international studies, non-random samples are accepted, because random samples cannot always be compared due to various influences (e.g.. age of subjects, level of education; see, e.g., Brislin \& Baumgardner, 1971; Lonner \& Berry, 1986). Holzmüller (1995, p. 242) recommends the use of matched samples in order to reduce the error of variance.

The population are part-time Executive MBA students with international experience. Both in the United States and Germany, students entering this program have management experience of an average of five years. This population was chosen for different reasons: First, managers with university education are the type of employees (e.g., educated professionals) likely to be sent on expatriate assignments. Second, the majority of students in the Executive MBA program have international working experience. Finally, the samples can be matched very well concerning education, age, and gender.

Only students having already worked with people from another nation (e.g., during an international assignment or within a team) are included in the study. The U.S. sample contains 54 managers at an average age of $34 ; 38 \%$ are female. In Germany, 58 managers completed the questionnaires. The average age of this sample is $30 ; 29 \%$ are female. 


\section{Qualitative Part: Identifying Intercultural Competencies Based on Experience}

In the first part of the study, the participants are asked to specify which capabilities have facilitated working with individuals from another nation. These qualitative data are gathered before the Executive MBA students answer the quantitative measures in the second part of the study in order to ensure that the skills and capabilities named in the questionnaires do not influence the participants.

The question in the U.S. sample is as follows:

The process of translation, retranslation, and comparison was repeated

"Which capabilities have facilitated your cooperation and teamwork with individuals from another nation?"

until semantic

differences could no longer be

Quantitative Part: Evaluating Intercultural Competencies Identified in Literature

In the following sections, the intercultural competencies, which have been identified in an international literature research, are described. Moreover, for every intercultural competency, the self-report measure utilized in the study is described.

The following criteria guided the selection of the measures in this study. All questionnaires have been based on a sound theoretical foundation and are valid for the U.S. culture and language as well as for the German ones. Three of the selected measures were not available in a German version and had to be translated and validated (namely, BASIC, the SPSI-R, and the SMS, which will be described in the following paragraphs). The German adaptations were developed based on the translation/back-translation method (Berry, 1989). In that process, the respective U.S. original was translated into German by a bilingual person. A second bilingual person translated the German version into English. Afterward, the original version and the retranslated version were compared and semantic differences were identified. The process of translation, retranslation, and comparison was repeated until semantic differences could no longer be found. Afterward, the German versions were empirically evaluated based on the recommended criteria by Hui and Triandis (1985), Meredith (1993), and Steenkamp and Baumgartner (1998) (e.g., measurement invariance). The validation studies are published in $\operatorname{Graf}(2002,2003,2004)$.

For the purpose of the study, the measures were modified as they do not assess to what extent the person possesses the certain capability, but to what extent the person judges the skill to be important for 
international tasks. Similarly, Dean and Popp (1990) adapted standardized measures in order to assess the importance of various skills for international assignments.

The introduction for the measures in the U.S. sample is as follows:

BASIC assesses eight dimensions of intercultural communication effectiveness.
"Below a series of competencies are listed. Please read them and respond as directed."

The following response options are offered:

1. This capability is not important for intercultural interactions.

2. This capability is moderately important for intercultural interactions.

3. This capability is important for intercultural interactions.

4. This capability is very important for intercultural interactions.

5. This capability is essential to intercultural interactions.

The participants completed the five (modified) measures in the order described below.

Intercultural Communication Skills. Intercultural communication skills have been identified in the majority of studies focusing on capabilities for international tasks (e.g., Bradford, Allen, \& Beisser, 1998; Cui \& Awa, 1992; Dean \& Popp, 1990; Gudykunst \& Lee, 2002; Martin \& Hammer, 1989; Wiseman, 2002; Wiseman, Hammer, \& Nishida, 1989).

The Behavioral Assessment Scale for Intercultural Communication Effectiveness (BASIC), developed by Koester and Olebe (1988), has been chosen to assess intercultural communication competence and will be used in a modified version. According to Spitzberg $(1989$, p. 246), BASIC is one of the most commonly used measures for intercultural effectiveness; for instance, Nishida (1985) and Ruben and Kealey (1979) utilized it in their studies. For the German sample, BASIC was translated and validated (Graf, 2002). BASIC assesses eight dimensions of intercultural communication effectiveness. Those dimensions were developed by Ruben (1976) and are as follows: (1) Display of Respect-the ability to express respect for another person, (2) Interaction Posture-the ability to respond to others in a non-judgmental way, (3) Orientation to Knowledge-how one explains the world, (4) Empathy-the capacity to "put oneself in another's shoes" in a communication, (5) Task Role Behaviors - verbal and nonverbal behaviors contributing 
to group problem-solving activities, (6) Relational Role Behaviors - verbal and nonverbal behaviors contributing to building or maintaining relationships in a group, (7) Interaction Behavior/Management - communication skill in governing interactions to meet the needs and desires of group members, and (8) Tolerance of Ambiguity - the ability to react to new and ambiguous situations with little visible discomfort. Each of the eight BASIC dimensions is assessed by one item.

Intercultural Sensitivity. The emotional capability to be sensitive toward individuals from a different national culture has been identified to be crucial for effective intercultural interactions by several authors (e.g., Abe \& Wiseman, 1983; Chen \& Starosta, 1996; Cui \& Awa, 1992; Fritz, Möllenberg, \& Chen, 2002; Koester \& Olebe, 1988; Martin, 1987).

The Intercultural Sensitivity Scale (ISS) by Chen and Starosta (2000) is selected to be modified for assessing this capability in the study. The German version by Fritz and Möllenberg (1999) is utilized for the German samples. The ISS is based on the authors' concept of intercultural sensitivity (Chen \& Starosta, 1996, 1997). The ISS consists of 24 items and is composed of five scales: (1) Engagement in Intercultural Interactions, (2) Respect for Cultural Differences, (3) Self-Confidence in Intercultural Interactions, (4) Enjoyment of Intercultural Interactions, and (5) Attentiveness in Intercultural Interactions.

Interpersonal Competence. The majority of studies concerning capabilities for international tasks emphasize the importance of interpersonal competence (e.g., Abe \& Wiseman, 1983; Cui \& Awa, 1992; Dean \& Popp, 1990; Hammer, 1987; Hammer, Gudykunst, \& Wiseman, 1978; Hawes \& Kealey, 1979; Kealey, 1989; Spitzberg \& Cupach, 1989).

For the study, the Interpersonal Competence Questionnaire (ICQ), which was developed by Buhrmester, Furman, Wittenberg, and Reis (1988), is selected. A modified adaptation based on the German version by Riemann and Allgöwer (1993) is utilized for the German sample. The ICQ contains 40 items assessing the following five domains of interpersonal competence: (1) Initiation of Interactions and Relationships, (2) Assertion of Personal Rights and Displeasure with Others, (3) Self-Disclosure of Personal Information, (4) Emotional Support of Others, and (5) Management of Interpersonal Conflicts. 
Social Problem-Solving Capability. Research recognizes social problemsolving capability to be a fundamental factor in cultural adjustment (Brislin, 1981; D'Zurilla, 1990; D'Zurilla \& Maydeu-Olivares, 1995; Miller, 1972) and acculturation (Ward, 1996). Social problem solving refers to the process with the help of which individuals attempt to identify, discover, or invent effective or adaptive

Several studies have identified self-monitoring to facilitate international tasks and intercultural interactions... coping responses for situations encountered in everyday life for which no effective response is immediately apparent or available (D'Zurilla \& Nezu, 1982). The Social Problem-Solving Inventory-Revised (SPSI-R) (D'Zurilla, Nezu, \& MaydeuOlivares, 1999) has been selected to assess social problem-solving capabilities in the study. For the German sample, the adaptation by Graf (2003) is utilized.

The SPSI-R assesses the following five dimensions of social problemsolving capability: (1) Positive Problem Orientation, (2) Negative Problem Orientation, (3) Rational Problem Solving, (4) Impulsivity/Carelessness Style, and (5) Avoidance Style. In the study, only Positive Problem Orientation and Rational Problem Solving are administered, the scales assessing dysfunctional problem-solving capabilities (Negative Problem Orientation, Impulsivity/Carelessness Style, and Avoidance Style) are not administered.

Self-Monitoring. Several studies have identified self-monitoring to facilitate international tasks and intercultural interactions (Gangestad \& Snyder, 2000; Gudykunst, 1985; Harrison, Chadwick, \& Scales, 1996; Kealey, 1989; Weierter, Ashkanasy, \& Callan, 1997). The concept of self-monitoring was originally defined by Snyder (1974) as self-observation and self-control guided by situational cues to social appropriateness.

Based on his concept of self-monitoring, Snyder (1974) developed the Self-Monitoring Scale (SMS), which was administered in the study. As the questionnaire had not been available in a German version, it was translated into German and empirically validated for the German samples (Graf, 2004).

\section{RESULTS}

\section{Qualitative Part (Research Questions 1a and 1b)}

The intercultural competencies named by the participants are presented in Table 1. Regarding research question la, the number of managers naming the intercultural competencies are counted. 
Table 1. Intercultural Competencies Stated by the Managers in the U.S. and German Samples

\begin{tabular}{lccc}
\hline & \multicolumn{3}{c}{ Number of participants } \\
& naming the competencies \\
\cline { 2 - 4 } & U.S. & German & Sample \\
Sample & Total \\
\hline 1. Speak Foreign Language & 41 & 40 & 81 \\
2. Openness & 19 & 39 & 58 \\
3. Knowledge of Culture, Religion, Customs, etc. & 21 & 30 & 51 \\
4. Diplomacy, Tolerance & 6 & 28 & 34 \\
5. Adaptability & 6 & 20 & 26 \\
6. Patience, Calmness & 10 & 8 & 18 \\
7. Empathy & 7 & 12 & 19 \\
8. Respect & 8 & 8 & 16 \\
9. Team Play Ability & 3 & 12 & 15 \\
10. Self-Confidence & 3 & 6 & 9 \\
11. Business Knowledge & 8 & - & 8 \\
12. Knowledge about Political and Monetary Differences & 6 & - & 6 \\
13. Analytical Ability & 6 & - & 6 \\
14. Previous Experience & - & 4 & 4 \\
15. Courtesy & - & 4 & 4 \\
16. Further Competencies & 10 & 5 & 15 \\
TOTAL & 154 & 216 & 370 \\
\hline
\end{tabular}

Differences between the samples are identified for research question $1 b$.

Both in the U.S. and German sample, the ability to speak the language of the interacting individual(s) is evaluated to be an important variable by the majority of participants. The subsequent priorities are openness and the knowledge of the culture, religion, and customs of the individual(s) from another nation. Diplomacy, tolerance, and adaptability are rated to be important by the German participants, whereas ten U.S. managers emphasize the importance of patience and calmness. Respect for people from other nations is judged to be significant by eight managers in each sample.

\section{Quantitative Part (Research Questions 2a and 2b)}

Table 2 shows the importance of the intercultural competencies that have been identified in the international literature research rated by the German and U.S. managers. For the purposes of answering research question $2 \mathrm{a}$, the relative importance of the competencies is assessed. U-Tests by Mann-Whitney are calculated in order to answer research question $2 \mathrm{~b}$. 
Table 2. Arithmetic Mean and U-Test by Mann-Whitney of the Results in the Modified Measures in the U.S. and German Samples

\begin{tabular}{|c|c|c|c|c|}
\hline Measure & Nation & $\mathrm{M}$ & $\mathrm{Z}$ & Sig. \\
\hline 1. BASIC- & USA & 3.83 & \multirow{2}{*}{-.35} & \multirow{2}{*}{$.000 * * *$} \\
\hline Respect & GER & 2.71 & & \\
\hline 2. BASIC- & USA & 3.71 & \multirow{2}{*}{-.21} & \multirow{2}{*}{$.035^{*}$} \\
\hline Posture & GER & 3.29 & & \\
\hline 3. BASIC- & USA & 3.77 & \multirow{2}{*}{-1.32} & \multirow{2}{*}{.185} \\
\hline Knowledge & GER & 3.48 & & \\
\hline 4. BASIC- & USA & 3.26 & \multirow{2}{*}{-.43} & \multirow{2}{*}{.667} \\
\hline Empathy & GER & 3.16 & & \\
\hline 5. BASIC- & USA & 3.03 & \multirow{2}{*}{-3.99} & \multirow{2}{*}{$.000 * * *$} \\
\hline Task & GER & 1.91 & & \\
\hline 6. BASIC- & USA & 3.20 & \multirow{2}{*}{-1.81} & \multirow{2}{*}{.070} \\
\hline Relational & GER & 2.69 & & \\
\hline 7. BASIC- & USA & 3.26 & \multirow{2}{*}{-3.05} & \multirow{2}{*}{$.002 * *$} \\
\hline Interaction & GER & 2.53 & & \\
\hline 8. BASIC- & USA & 3.80 & \multirow{2}{*}{-2.54} & \multirow{2}{*}{$.011^{*}$} \\
\hline Ambiguity & GER & 3.23 & & \\
\hline 9. ISS- & USA & 3.85 & \multirow{2}{*}{-4.47} & \multirow{2}{*}{$.000 * * *$} \\
\hline Engagement & GER & 2.70 & & \\
\hline $\begin{array}{l}\text { 10. ISS- } \\
\text { Respect }\end{array}$ & USA & 4.51 & -.25 & .799 \\
\hline 11. ISS- & USA & 3.40 & \multirow{2}{*}{-4.13} & \multirow{2}{*}{$.000 * * *$} \\
\hline Confidence & GER & 2.20 & & \\
\hline 12. ISS- & USA & 3.60 & \multirow{2}{*}{-.60} & \multirow{2}{*}{.543} \\
\hline Enjoyment & GER & 3.75 & & \\
\hline 13. ISS- & USA & 3.68 & \multirow{2}{*}{-3.52} & \multirow{2}{*}{$.000^{* * *}$} \\
\hline Attentiveness & GER & 2.70 & & \\
\hline 14. ICQ- & USA & 3.23 & -36 & 018 * \\
\hline Initiation & GER & 2.80 & -.50 & .010 \\
\hline 15. ICQ- & USA & 2.80 & -3.07 & $.002 * *$ \\
\hline Assertion & GER & 2.00 & -0.07 & .002 \\
\hline 16. ICQ- & USA & 2.57 & -.21 & .830 \\
\hline Disclosure & GER & 2.61 & -.21 & \\
\hline 17. ICQ- & USA & 2.48 & -1.07 & .285 \\
\hline Support & GER & 2.24 & -1.07 & .285 \\
\hline 18. ICQ- & USA & 3.11 & -2.06 & $.039 *$ \\
\hline Conflict & GER & 2.54 & -2.00 & \\
\hline 19. SPSI-R & USA & 3.08 & -1.54 & .121 \\
\hline PPO & GER & 2.63 & 1.01 & \\
\hline 20. SPSI-R & USA & 3.08 & -3.71 & $.000 * * *$ \\
\hline RPS & GER & 1.89 & -0.11 & \\
\hline 21. SMS & USA & 2.29 & -5.65 & $.000 * * *$ \\
\hline total score & GER & 3.12 & -5.05 & n \\
\hline
\end{tabular}

Notes: ${ }^{*} \mathrm{p} \leq .05 ;{ }^{* *} \mathrm{p} \leq .01 ;{ }^{* *} \mathrm{p} \leq .001$

GER $=$ Germany

$\mathrm{PPO}=$ Positive Problem Orientation

RPS $=$ Rational Problem Solving 
Both samples evaluate "Respect for Cultural Differences" (assessed by the modified ISS) to be the most important intercultural competency. Accordingly, the dimension "Display of Respect" in the modified version of BASIC is rated to be significant. "Orientation to Knowledge" (assessed by the modified BASIC) is judged to be the second most important intercultural competency by U.S. and German managers, followed by "Tolerance of Ambiguity" (assessed by the modified BASIC) and "Enjoyment of Intercultural Interactions" (assessed by the modified ISS).

U-Tests by Mann-Whitney show that from 21 dimensions assessed, the samples significantly differ in 13. The U.S. managers attribute a higher importance to 12 of the intercultural competencies: "Display of Respect" (modified BASIC), "Interaction Posture" (modified BASIC), "Task Role Behaviors" (modified BASIC), "Interaction Behavior/Management" (modified BASIC), "Tolerance of Ambiguity" (modified BASIC), "Engagement in Intercultural Interactions" (modified ISS), "Self-Confidence in Intercultural Interactions" (modified ISS), "Attentiveness in Intercultural Interactions" (modified ISS), "Initiation of Interactions and Relationships" (modified ICQ), "Assertion of Personal Rights and Displeasure with Others" (modified ICQ), "Management of Interpersonal Conflicts" (modified ICQ), and "Rational Problem Solving" (modified SPSI-R). The German sample rates one intercultural competency, "SelfMonitoring" (modified SMS), to be significantly more important than the U.S. sample.

\section{Answering the Research Questions}

Research questions $1 \mathrm{a}$ and $2 \mathrm{a}$ are related to the issue of significant intercultural competencies for expatriate selection. Research questions $1 \mathrm{~b}$ and $2 \mathrm{~b}$ analyze differences between the U.S. and German sample.

Research Question 1a: The ability to speak the language of the interacting individual(s) is judged to be the most important intercultural competency in both samples. U.S. and German managers have also experienced the ability to be open toward other cultures and the knowledge of the culture, religion, and customs of the interacting individual(s) to help facilitate international tasks. The next most important priorities are diplomacy/tolerance and adaptability. Several managers in both samples rate "Respect for Cultural Differences" to be an essential characteristic for successful intercultural interactions.

Research Question 1b: This question, asking for differences between the U.S. and German sample in the qualitative study, cannot be 
...selfmonitoring receives a low rating from the U.S. participants but a high one from the German sample. answered in the affirmative or the negative. On the one hand, there are significant differences among the named intercultural competencies. On the other hand, in both samples, managers name language capabilities, openness, and the knowledge of culture, religions, and customs most frequently. Consequently, the samples correspond in the most important intercultural competencies, but not in the subsequent priorities.

Research Question 2a: Both samples evaluate dimensions of intercultural communication skills and intercultural sensitivity to be significant for international tasks. U.S. and German managers judge interpersonal competence to be less important. Social problemsolving capabilities are considered to be significant by the U.S. participants but less meaningful by the German managers. Finally, self-monitoring receives a low rating from the U.S. participants but a high one from the German sample.

Looking at the single dimensions of the scales reveals that both samples judge "Respect" (assessed by the modified BASIC as well as by the modified ISS) to be the most important intercultural competency, followed by "Orientation to Knowledge" (assessed by the modified ISS). The order of precedence of the further competencies differs between the two samples.

Research Question 2b: This question, asking whether the results in the quantitative study differ between the samples, is answered in the affirmative. U-Tests by Mann-Whitney show that out of the 21 dimensions assessed, 13 receive significantly different evaluations by the two samples.

\section{DISCUSSION AND CONCLUSIONS}

An empirical study in the United States and Germany is conducted in order to identify significant intercultural competencies for international tasks. Moreover, it gathers information concerning the controversy of whether expatriate selection should be based on culture-specific or culture-general profiles.

\section{Conclusions on Significant Intercultural Competencies for Expatri- ate Selection}

The first research question evaluated which competencies have been experienced to be important in international tasks by managers in the United States and Germany. The results associated with this research 
question indicate that the ability to speak the language of the interacting individual(s) and knowledge about the foreign culture are significant intercultural competencies. Interestingly, these capabilities have not been identified in international literature research and, consequently, do not seem to be widely verified in literature. Concerning language skills, authors often emphasize that their relative importance is secondary for international tasks: "Knowing how to listen, how to interrupt, how to praise, and how to scold, are more important for a foreign manager than learning the language" (Berger, 1987 , p. 61). However, studies show that insufficient language capabilities enhance the risk of misunderstandings (Brislin, 1981) and complicate effective cooperation (Chen \& Starosta, 1996). Turning to the knowledge about the foreign culture, it can be concluded that this variable is neglected in intercultural research. For example, the cognitive component in Spitzberg's (2000) model of intercultural communication competence "knowledge functions" describes aspects like "cognitive complexity" - that is, the ability to deal with and process information; the knowledge of cultural characteristics is not included.

Research question $2 \mathrm{a}$ assessed which intercultural competencies identified in literature are verified to be important for international tasks by U.S. and German managers. The results of the study show that U.S. and German managers confirm that intercultural communication skills and intercultural sensitivity substantially facilitate international tasks. Interpersonal competence is judged to be less important in international working cooperations. Regarding social problemsolving capabilities and self-monitoring, results differ between the samples. U.S. managers attribute a higher importance to social problem solving than the German participants and thus verify that this capability constitutes an important intercultural competency, whereas the German managers have experienced self-monitoring to be a significant intercultural competency.

Regarding the single dimensions of intercultural competencies referring to this research question, it becomes obvious that managers from the United States and Germany judge the ability to display respect to be the most important intercultural competency. This finding confirms Ruben and Kealey's (1979, p. 38) conclusion that respect for cultural differences may predict effective intercultural interactions. However, this competency is rarely considered in expatriate selection processes (e.g., Mendenhall, Dunbar, \& Oddou, 1987, p. 333; Tung, 1981; Weber, Festing, Dowling, \& Schuler, 2001, p. 128). 
Managers in both nations evaluate "Orientation to Knowledge"that is, the pattern of how to explain and attribute behaviors and circumstances-to be the second most important dimension of intercultural competencies. Presumably, the more a person understands and recognizes that knowledge is individual in nature, the less

Generally, intercultural competencies that may be developed short-term are inferior in personnel selection processes... difficulty he or she has in adjusting to other people in other cultures whose views are likely to be quite different from his or her own (Ruben \& Kealey, 1979, p. 17). Although the importance of this dimension is supported by several authors under a variety of labels (e.g. Barna, 1994; Bochner \& Kelly, 1974; Gudykunst, Wiseman, \& Hammer, 1977), it has not attracted attention in expatriate selection (Kealey, 1996).

Summing up, U.S. and German managers judge language capabilities, intercultural knowledge, intercultural communication competence, and intercultural sensitivity to be crucial for international tasks. Generally, intercultural competencies that may be developed shortterm are inferior in personnel selection processes and thus are important for management development. Language capabilities and knowledge about foreign cultures can (easily) be learned by expatriates and thus should not necessarily be included in the selection profile. In contrast, intercultural communication competence and intercultural sensitivity can be developed only partially and only on a long-term basis. Consequently, these intercultural competencies should be screened thoroughly in expatriate selection procedures.

\section{Conclusions on Culture-General versus Culture-Specific Skill Profiles}

Two research questions ( $1 \mathrm{~b}$ and $2 \mathrm{~b}$ ) evaluated whether the results concerning important intercultural competencies for international tasks differ between the U.S. and German managers. The results associated with these research questions support both a culture-general and culture-specific skill profile for expatriate selection.

In the qualitative part of the study, U.S. and German managers essentially name similar intercultural competencies to be very important (namely, speak the foreign language, openness, and intercultural knowledge). However, there are differences in the subsequent priorities. For example, several U.S. managers judge the knowledge about political and monetary differences to be important, whereas none of the German managers are of that opinion.

Similarly, in the quantitative part of the study, U.S. and German managers agree on which intercultural competencies are most important 
(namely, intercultural communication skills and intercultural sensitivity). However, it shows that out of 21 dimensions assessed, U.S. and German ratings significantly differ in 13. Interestingly, the U.S. managers judge 12 dimensions to be more important than the German participants. Incidentally, Dean and Popp (1990), comparing the importance of intercultural skills judged by U.S. and French managers, also discovered that the U.S. participants gave higher ratings about the importance of several competencies than the French. Consequently, the expectations toward expatriates in the United States seem to be higher than in Germany (or France).

Summing up, the findings supply evidence for culture-general and culture-specific intercultural competencies. Managers in the United States as well as Germany judge intercultural communication skills and intercultural sensitivity to be significant when working with culturally different others. Thus, these competencies may be useful in a culture-general profile. However, there seem to be culture-specific differences about important intercultural competencies for international tasks in the United States and Germany. Therefore, expatriate selection should additionally include a culture-specific assessment.

\section{Measuring Intercultural Competencies}

The questionnaires identified in international literature research can be used for assessing intercultural competencies in expatriate selection. In general, the advantage of self-report measures is "that an individual knows more about him- or herself than does anyone else" (Spitzberg \& Cupach, 1989, p. 57). However, as with many selfreport measures, the item transparency is fairly high (i.e., it would be easy for applicants to discern the "best" answer and thus slant scores in the desired direction). Indeed, Kealey (1996) contends that the issue of socially desirable responding is "extraordinarily high on these tests when used for overseas screening” (p. 97). Alternatively, assessment center procedures specifically targeted toward international contexts may be applied to screen the candidate's suitability for foreign assignment in order to avoid some of the problems inherent in self-report measures. For example, Kealey (1996) notes that assessment centers "offer the most potential for effective international screening” (p. 101). An assessment center provides a variety of techniques for evaluating candidates (e.g., role plays, behavioral observations, case studies, tests, and group activities). Another potential avenue for screening the identified intercultural competencies may involve interviews utilizing Flanagan's Critical Incident Technique (1954), the utility of which has been poorly examined for expatriate

An assessment center provides a variety of techniques for evaluating candidates. 
screening (Stahl, 1998). Additionally, the usefulness of tools such as the Intercultural Sensitizer (also known as the Culture Assimilator; Cushner \& Brislin, 2000) for expatriate selection still has to be fully examined. In their 1996 handbook chapter, Cushner and Landis provide detailed guidelines for constructing and using Intercultural Sensitizers in intercultural training contexts. It seems possible that culture-specific and culture-general Intercultural Sensitizers could also be used in selection or screening contexts to assess existing levels of some of the identified intercultural competencies.

\section{Study Limitations and Future Research}

The current study has several limitations to be considered in evaluating the results. One major limitation is that only two (Western) nations are included in the study. Therefore, the findings can be generalized to other Western nations only in a restricted way; however, they cannot be applied to non-Western cultures. Moreover, only five intercultural competencies are evaluated in the quantitative part of the study-leaving open the possibility that other intercultural competencies would have exhibited different results.

Another potential limitation of this research project concerns the use of self-report measures, considering the threats to validity associated with self-report measures. The major threat is a potential systematic bias that occurs when individuals misrepresent or misinterpret their own behavior (Paulhus, 1986). An alternative data source for the studies would have been to utilize non-self-report measures (e.g., peer ratings). However, partner or third-party evaluations pose other serious methodological challenges (Spitzberg \& Cupach, 1989, pp. 58-61).

Future research should try to replicate and extend the focus of the studies. Since the selection of nations may have biased the findings, other, preferably non-Western nations should be included to test the validity of the results.

\section{REFERENCES}

Abe, H. \& Wiseman, R. (1983). A cross-cultural confirmation of the dimensions of intercultural effectiveness. International Journal of Intercultural Relations, 7, 53-67.

Allerton, H. (1997). Expatriate gaps. Training \& Development, 51(7), 7-8.

Barna, L. M. (1994). Stumbling blocks in intercultural communication. In L. A. Samovar \& R. E. Porter (Eds.), Intercultural communication: A reader (pp. 337-346). Belmont: Wadsworth. Bennett, R., Aston, A., \& Colquhoun, T. (2000). Cross-cultural training: A critical step in ensuring the success of international assignments. Human Resource Management, 39, 239-250. 
Berger, M. (1987). Building bridges over the cultural rivers. International Management, 42, 61-72.

Berry, J. W. (1989). Introduction to methodology. In H. Triandis \& J. W. Berry (Eds.), Handbook of cross-cultural psychology, 2 (pp. 1-28). Boston: Allyn \& Bacon.

Black, J., Mendenhall, M., \& Oddou, G. (1991). Towards a comprehensive model of international adjustment: An integration of multiple theoretical perspectives. Academy of Management Review, 16(2), 291-317.

Bochner, A. P., \& Kelly, C. W. (1974). Interpersonal competence: Rationale, philosophy, and implementation of a conceptual framework. Speech Teacher, 23, 279-301.

Boles, M. (1997). Expatriation: Economic aspects. Workforce, 76(8), 21-22.

Bolino, M., \& Feldman, D. (2000). Increasing the skill utilization of expatriates. Human Resource Management, 39, 367-379.

Bradford, L., Allen, M., \& Beisser, K. (1998). An evaluation and meta-analysis of intercultural competence research. Research report, University of Wisconsin-Milwaukee.

Brislin, R. (1981). Cross-cultural encounters: Face-to-face encounters. New York: Pergamon.

Brislin, R., \& Baumgardner, S. R. (1971). Non-random sampling of individuals in crosscultural research. Journal of Cross-Cultural Psychology, 4, 397-400.

Buhrmester, D., Furman, W., Wittenberg, M., \& Reis, H. (1988). Five domains of interpersonal competence in peer relationships. Journal of Personality and Social Psychology, 55, 991-1008.

Chen, G.-M., \& Starosta, W. J. (1996). Intercultural communication competence: A synthesis. In B. Burleson (Ed.), Communication yearbook 19 (pp. 353-383). Thousand Oaks, CA: Sage. Chen, G.-M., \& Starosta, W. J. (1997). A review of the concept of intercultural sensitivity. Human Communication, 1, 1-16.

Chen, G.-M., \& Starosta, W. J. (2000). The development and validation of the intercultural communication sensitivity scale. Human Communication, 3, 1-15.

Copeland, L., \& Griggs, L. (1986). Going international: How to make friends and deal effectively in the global marketplace. New York: New American Library.

Cui, G., \& Awa, N. E. (1992). Measuring intercultural effectiveness: An integrative approach. International Journal of Intercultural Relations, 16, 311-328.

Cushner, K., \& Brislin, R. W. (2000). Intercultural interactions. A practical guide. Thousand Oaks, CA: Sage.

Cushner, K., \& Landis, D. (1996). The intercultural sensitizer. In D. Landis \& R. S. Bhagat, (Eds.), Handbook of intercultural training (pp. 185-202). Thousand Oaks, CA: Sage.

Dean, O., \& Popp, G. E. (1990). Intercultural communication effectiveness as perceived by American managers in Saudi Arabia and French managers in the U.S. International Journal of Intercultural Relations, 14, 405-424.

Dinges, N. G., \& Baldwin, K. D. (1996). Intercultural competence. A research perspective. In D. Landis \& R. S. Bhagat (Eds.), Handbook of intercultural training (pp. 106-123). Thousand Oaks, CA: Sage.

D’Zurilla, T. J. (1990). Problem-solving training for effective stress management and prevention. Journal of Cognitive Psychotherapy: An International Quarterly, 4, 327-355.

D'Zurilla, T. J., \& Maydeu-Olivares, A. (1995). Conceptual and methodological issues in social problem-solving assessment. Behaviour Therapy, 26, 409-432.

D’Zurilla, T. J., \& Nezu, A. M. (1982). Social problem-solving in adults. In P. C. Kendall (Ed.), Advances in cognitive-behavioral research and therapy, 1 (pp. 201-274). New York: Academic Press.

D'Zurilla, T. J., Nezu, A. M., \& Maydeu-Olivares, A. (1999). Manual for the social problemsolving inventory revised (SPSI-R). North Tonawanda, NY: Multi-Health Systems Inc.

Flanagan, J. (1954). The critical incident technique. Psychological Bulletin, 52, 327-358.

Forster, N. (2000). Expatriates and the impact of cross-cultural training. Human Resource Management Journal, 10(3), 63-78.

Fritz, W., \& Möllenberg, A. (1999). Die Messung der interkulturellen Sensibilität in verschiedenen Kulturen-Eine internationale Vergleichsstudie. Technical University of Braunschweig.

Fritz, W., Möllenberg, A., \& Chen, G.-M. (2002). Measuring intercultural sensitivity in different cultural contexts. Intercultural Communication Studies, 11(2), 165-176. 
Gangestad, S. W., \& Snyder, M. (2000). Self-monitoring: Appraisal and reappraisal. Psychological Bulletin, 126, 530-555.

Graf, A. (2002). Eine deutschsprachige Version der behavioural assessment scale for intercultural communication effectiveness. Unpublished manuscript, Technical University of Braunschweig.

Graf, A. (2003). Psychometrische Überprüfung einer deutschsprachigen Übersetzung des SPSI-R. Zeitschrift für Differentielle und Diagnostische Psychologie, 24, 277-291.

Graf, A. (2004). Eine deutschsprachige Version der self-monitoring scale. Zeitschrift für Arbeits- und Organisationspsychologie, 48, 9-12.

Gudykunst, W. B. (1985). The influence of cultural similarity, type of relationship and selfmonitoring on uncertainty reduction processes. Communication Monographs, 52, 203-217.

Gudykunst, W. B., \& Lee, C. M. (2002). Cross-cultural communication theories. In W. B. Gudykunst \& B. Mody (Eds.), Handbook of international and intercultural communication (pp. 25-50). Thousand Oaks, CA: Sage.

Gudykunst, W. B., Wiseman, R. L. \& Hammer, M. R. (1977). Determinants of a sojourner's attitudinal satisfaction: A path model. In B. D. Ruben (Ed.), Communication yearbook 1 (pp. 415-425). Thousand Oaks, CA: Sage.

Hammer, M. R. (1987). Behavioural dimensions of intercultural effectiveness: A replication and extension. International Journal of Intercultural Relations, 11, 65-88.

Hammer, M. R., Gudykunst, W. B., \& Wiseman, R. L. (1978). Dimensions of intercultural effectiveness: An exploratory study. International Journal of Intercultural Relations, 2, 382-392.

Hammer, M. R., Nishida, H., \& Wiseman, R. L. (1996). The influence of situational prototypes on dimensions of intercultural communication competence. Journal of Cross-Cultural Psychology, 27, 267-282.

Harrison, J. K., Chadwick, M., \& Scales, M. (1996). The relationship between cross-cultural adjustment and the personality variables of self-efficacy and self-monitoring. International Journal of Intercultural Relations, 20(2), 167-188.

Hawes, F., \& Kealey, D. J. (1979). Canadians in development: An empirical study of adaptation and effectiveness on overseas assignment-Technical report. Ottawa: Canadian International Development Agency.

Holzmüller, H. H. (1995). Konzeptionelle und methodische Probleme in der interkulturellen Management- und Marketingforschung. Stuttgart: Schäffer-Poeschel.

Hui, H., \& Triandis, H. (1985). Measurement in cross-cultural psychology: A review and comparison of strategies. Journal of Cross-Cultural Psychology, 16, 131-152.

Kealey, D. J. (1989). A study of cross-cultural effectiveness: Theoretical issues, Practical applications. International Journal of Intercultural Relations, 13, 233-246.

Kealey, D. (1996). The challenge of international personnel selection. In D. Landis \& R. S. Bhagat (Eds.), Handbook of intercultural training (pp. 81-105). Thousand Oaks, CA: Sage.

Kealey, D. J., \& Ruben, B. D. (1983). Cross-cultural personnel selection: Criteria, issues and methods. In D. Landis \& R. W. Brislin (Eds.), Handbook of intercultural training, 1 (pp. 155-175). New York: Pergamon.

Koester, J., \& Olebe, M. (1988). The behavioural assessment scale for intercultural communication effectiveness. International Journal of Intercultural Relations, 12, 233-246.

Kraimer, M. W., Wayne, S., \& Jaworski, R. (2001). Sources of support and expatriate performance: The mediating role of expatriate adjustment. Personnel Psychology, 54, 71-99.

Lonner, W. J., \& Berry, J. W. (1986). Sampling and surveying. In W. J. Lonner \& J. W. Berry (Eds.), Field methods in cross-cultural research (pp. 85-110). Beverly Hills, CA: Sage.

Martin, J. N. (1987). The relationships between student sojourner perceptions of intercultural competencies and previous sojourn experience. International Journal of Intercultural Relations, 11, 337-355.

Martin, J. N., \& Hammer, M. R. (1989). Behavioural categories of intercultural communication competence: Everyday communicator's perceptions. International Journal of Intercultural Relations, 13, 303-332.

Mendenhall, M. E., Dunbar, E., \& Oddou, G. R. (1987). Expatriate selection, training and career-pathing: A review and critique. Human Resource Management, 26, 331-345.

Meredith, W. (1993). Measurement invariance, factor analysis and factorial invariance. Psychometrika, 58, 525-543. 
Miller, E. L. (1972). The overseas assignment: How managers determine who is to be selected. Michigan Business Review, 24, 12-19.

Nishida, H. (1985). Japanese intercultural communication competence and cross-cultural adjustment. International Journal of Intercultural Relations, 9, 247-269.

Paulhus, D. L. (1986). Self-deception and impression management in test responses. In A. Angleitner \& J. S. Wiggins (Eds.), Personality assessment via questionnaires (pp. 143-165). Berlin: Springer.

Riemann, R., \& Allgöwer, A. (1993). Eine deutschsprachige Fassung des "interpersonal competence questionnaire" (ICQ). Zeitschrift für Differentielle und Diagnostische Psychologie, 14(3), 153-163.

Ruben, B. D. (1976). Assessing communication competency for intercultural adaptation. Group \& Organization Studies, 1, 334-354.

Ruben, B. D., \& Kealey, D. J. (1979). Behavioural assessment of communication competency and the prediction of cross-cultural adaptation. International Journal of Intercultural Relations, $3,15-47$.

Shaffer, M., Harrison, D., \& Gilley, K. (1999). Dimensions, determinants and differences in the expatriate adjustment process. Journal of International Business Studies, 30, 557-581.

Snyder, M. (1974). Self-monitoring of expressive behaviour. Journal of Personality and Social Psychology, 30(4), 526-537.

Solomon, C. (1996). Danger below! Spot failing global assignments. Personnel Journal, 75(11), 78-83.

Spitzberg, B. H. (1989). Issues in the development of a theory of interpersonal competence in the intercultural context. International Journal of Intercultural Relations, 13, 241-268.

Spitzberg, B. H. (2000). A model of intercultural communication competence. In L. Samovar \& R. Porter (Eds.), Intercultural communication: A reader (pp. 375-387). Belmont: Wadsworth Publishing.

Spitzberg, B. H., \& Cupach, W. R. (1989). Handbook of interpersonal competence research. New York: Springer.

Stahl, G. (1998). Internationaler Einsatz von Führungskräften. München: Oldenbourg.

Steenkamp, J.-B., \& Baumgartner, H. (1998). Assessing measurement invariance in crossnational consumer research. Journal of Consumer Research, 25, 78-90.

Swakk, R. (1995). Expatriate failures: Too many, too much cost, too little planning. Compensation and Benefits Review, 27(6), 47-55.

Tung, R. L. (1981). Selection and training of personnel for overseas assignments. Columbia Journal of World Business, 16, 68-78.

Ward, C. (1996). Acculturation. In D. Landis \& R. S. Bhagat (Eds.), Handbook of intercultural training (pp. 124-147). Thousand Oaks, CA: Sage.

Weber, W., Festing, M., Dowling, P. J., \& Schuler, R. S. (2001). Internationales Personalmanagement. Wiesbaden: Gabler.

Weierter, S. J., Ashkanasy, N. M., \& Callan, V. J. (1997). Effect of self-monitoring and national culture on follower perceptions of personal charisma and charismatic message. Australian Journal of Psychology, 49(2), 101-105.

Wiseman, R. L. (2002). Intercultural communication competence. In W. B. Gudykunst \& B. Mody (Eds.), Handbook of international and intercultural communication (pp. 207-224). Thousand Oaks, CA: Sage.

Wiseman, R. L., Hammer, M. R., \& Nishida, H. (1989). Predictors of intercultural communication competence. International Journal of Intercultural Relations, 13, 349-370. 